\title{
PATRIMÔNIO FESTIVO, ÉTNICO E TERAPÊUTICO: RELIGIÕES AFRO-BRASILEIRAS E CULTURA QUILOMBOLA
}

\section{FESTIVE, ETHNIC AND THERAPEUTIC HERITAGE: AFRO-BRASILIAN RELIGIONS AND QUILOMBOLA CULTURE}

\section{Fátima Tavares}

fattavares@ufba.br

Doutora em Antropologia pela UFRJ. Professora Titular do Departamento de Antropologia da UFBA e Professora Permanente no PPGA/UFBA.

ORCID: https://orcid.org/0000-0001-6668-4300

\section{Francesca Bassi}

f.yansa@gmail.com

PhD em Antropologia pela Universidade de Montréal. Professora Adjunta no CECULT da UFRB.

ORCID: https://orcid.org/0000-0002-8097-4619

\section{Carlos Caroso}

caroso@ufba.br

PhD em Antropologia pela UCLA. Professor Titular no Departamento de Antropologia da UFBA e Professor Permanente no PPGA/UFBA.

ORCID: http://orcid.org/0000-0001-5788-0385

\section{RESUMO}

Nos territórios quilombolas do município de Cachoeira, Bahia, observa-se um processo de florescimento cultural com algumas iniciativas de patrimonialização mobilizadas pelas comunidades. Nesse processo tem especial destaque a cultura afro-religiosa para uma parcela dessas comunidades, afinando-se a tendências mais amplas de inclusão gradual dos bens culturais das populações minoritárias, ampliando, assim, o escopo dos "bens culturais". Neste artigo apresentamos algumas dessas iniciativas, a exemplo da Festa de São Roque e os peditórios da Esmola Cantada; de implantação do turismo étnico de base comunitária da Rota da Liberdade; de revalorização das terapêuticas tradicionais; e de mobilização político-cultural afro-religiosa da Festa da Ostra, locus de visibilização e inventividade de símbolos e experiências dessas comunidades. Nessas iniciativas, referentes materiais, sensoriais e estéticos afro-religiosos comparecem na fundamentação das "políticas de autenticidade" para a patrimonialização da cultura quilombola.

Palavras-chave: quilombo; patrimônio; religiões afro-brasileiras.

\section{ABSTRACT}

In the quilombola territories of Cachoeira, Bahia, there is a process of cultural flourishing with some heritage initiatives mobilized by the communities. In 
this process, Afro-religious culture has a special emphasis on a portion of these communities, in tune with the broader trends of gradual inclusion of the cultural assets of minority populations, thereby broadening the scope of the "cultural assets". In this article we present some of these initiatives, such as the Festa de São Roque and the petitory of Esmola Cantada; the community-based ethnic tourism on the Freedom Route; revaluation of traditional therapies; and Afro-religious political-cultural mobilization, locus of visibility and inventiveness of symbols and experiences of these communities. In these initiatives, material, sensory and Afro-religious aesthetics refer to the foundation of the "authenticity policies" for the heritage of quilombola culture.

Keywords: quilombo; heritage; Afro-brazilian religions.

\section{INTRODUÇÃO}

Pode-se dizer que nos territórios quilombolas do município de Cachoeira, Bahia, observa-se um processo de florescimento cultural (no sentido que é apresentado por Sahlins, 1997), se quisermos com isso evocar as poderosas transformações em curso, que vem redesenhando a autopercepção de parcela expressiva dos habitantes dessa região. São comunidades que se organizam tendo como referência o Conselho Quilombola da Bacia e Vale do Iguape, distrito de mesmo nome, no município situado no entorno e proximidades da Reserva Extrativista (RESEX) Marinha Baía do Iguape. O Conselho foi fundado no ano de 2008, no bojo do processo de lutas desencadeadas nas comunidades desde os anos de 1990 (CRUZ, 2014; CARVALHO, 2016; SANTOS; JOVELINO; SILVA, 2019), agregando atualmente 15 comunidades ${ }^{1}$.

Nesse processo tem especial destaque a cultura afro-religiosa para uma parcela dessas comunidades, que é ativada no fortalecimento e valorização da cultura quilombola por meio de iniciativas que vão ao encontro de tendências mais amplas de inclusão gradual dos bens culturais das populações minoritárias, ampliando o escopo do que se considerava como "bens culturais", que até então estavam centrados no patrimônio católico barroco (CAPONE; MORAIS, 2015, p. 8). São iniciativas que retomam práticas religiosas tradicionais, tais como a Festa de São Roque que ocorre no mês de fevereiro, sendo antecedida pelos peditórios da Esmola Cantada que ocorrem no mês de janeiro em busca de angariar donativos para o festejo a implantação do turismo étnico de base comunitária na denominada Rota da Liberdade; a revalorização das terapêuticas tradicionais; e a mobilização político-cultural afro-religiosa da Festa da Ostra, como locus de visibilização de símbolos e experiências dessas comunidades.

Desde finais de 2013 nos encontramos envolvidos com pesquisas e atividades nessas comunidades, implicando em demandas por reconhecimento de direitos que se materializam no acesso à terra e no reconhe- 
cimento cultural. Em trabalho anterior (CAROSO; TAVARES; BASSI, 2018) apontávamos para as ambiguidades dessa condição diferenciada, que implica, ao mesmo tempo, em valorização e vulnerabilidade da cultura quilombola, cujo horizonte da patrimonialização cultural combina memórias e esquecimentos.

Articulado a esse movimento, também é preciso considerar que embora todas as comunidades quilombolas da Bacia e Vale do Iguape participem na luta por reconhecimento e direitos, o fazem de formas variadas. Neste trabalho nos deteremos naquelas que mobilizam as conexões entre religiões afro-brasileiras e cultura quilombola como elementos diacríticos da cultura: a umbanda e a religiosidade afro-católica fundamentando as identidades do Kaonge, Dendê, Kalembá, Engenho da Ponte e Engenho da Praia, diferenciando-as de outras comunidades próximas. Poderíamos falar, então, de uma "política de autenticidade" afro-religiosa nos termos de Meyer (2019), que não exclui outros referentes de autenticidade da cultura quilombola dessa região (comunidades com marcada presença evangélica, por exemplo, não são considerados menos "autênticas"), mas que certamente intensifica certas conexões entre estética, mídia e patrimonialização.

De toda forma, e apesar dessas diferenças, no trabalho já citado também sinalizamos o interesse dos nossos interlocutores (e a consequente demanda para nós, pesquisadores) por relatos que produzam outras "composições" do social, que reagreguem a cultura quilombola em novas condições de felicidade, no sentido atribuído por Latour (2012). Temos feito esse trabalho, nomeado por eles de "parceria", no qual são demandados relatórios antropológicos, mapeamentos, assessoramento em editais e eventos, e destacadamente a produção de cartas quilombolas ${ }^{2}$.

Nossa participação, ainda que pontual, nesses empreendimentos, nos leva a refletir acerca dos argumentos de Comaroff e Comaroff (2003) e Chari e Donner (2010) sobre a postura do etnógrafo em campo, que se torna crescentemente participativa e ativa, como resultado da proposta da antropologia decolonial e estabelecimento de novas relações entre etnógrafos e seus interlocutores. Mas esses desafios nos colocam em encruzilhadas, ao considerar por um lado, as controvérsias em torno da autenticidade nas transformações da etnicidade "corporativa", apontados pelos acima citados Camaroff e Comaroff (2011); por outro, a posição de Anjos (2006, p. 115) acerca da necessidade dos pesquisadores escaparem da "velha vigilância policialesca contra a emergência politizada da diferença étnica”, com juízos de valor disfarçados em análises sobre o que seria ou não autêntico na dinâmica da cultura. Acresce-se a isso a condição de "branquitude" dos autores deste trabalho na produção de narrativas afrodescendentes, conforme vem sendo denunciado em debates contemporâneos na antropologia (PINHO, 2019).

Neste artigo destacamos algumas iniciativas quilombolas que apontam na direção da mobilização dos referentes afro-religiosos na cultura 
patrimonializada: a) do Edital de cultura popular que requalifica a Festa de São Roque; b) do mapeamento do território na implantação do turismo étnico e a emergência da cultura patrimonializada; c) da valorização dos saberes e práticas terapêuticas por meio de mapeamento realizado em que participaram alguns interlocutores; d) por fim, da Festa da Ostra, misto de "vitrine" e "usina" de criatividade quilombola. Estivemos implicados na primeira, terceira e quarta iniciativas, o que nos leva também a uma rememoração dos nossos percursos, enquanto observadores direcionados, por esses territórios.

\section{PATRIMÔNIO CULTURAL IMATERIAL E A PERSPECTIVA "ETNOLÓGICA"}

O envolvimento das comunidades quilombolas em ações de fortalecimento da cultura comunitária nos remete a um "ponto de vista etnológico" (CHASTEL, 1997, apud ADELL, 2016) sobre patrimônio que, como foi argumentado por Adell (2016), comporta uma substituição da lógica do Tempo para uma lógica do Espaço. Trata-se, como escreve esse autor, de um novo marco, que corresponde, também, a um "giro espacial” e a uma virada pragmática, já que as situações, as ações, os contextos de enunciação, os processos de recepção e sua interpretação pelos indivíduos são responsáveis pela constituição do que reconhecemos como patrimônio cultural. Os dispositivos/termos da Convenção para a Salvaguarda do Patrimônio Cultural Imaterial (UNESCO, 2003) enfatizam o lugar reservado aos atores, assim como a consequente reflexividade sobre a cultura, que cria "uma nova perspectiva ética do Patrimônio Cultural Imaterial e, de forma mais geral, do patrimônio 'novo estilo' como um todo" (ADELL, 2016, p. 27).

Sobre esse estilo, deve-se entender uma moral aberta (POULOT, 2001, apud ADELL, 2016), menos presa aos cânones estéticos e éticos estabelecidos (os que fazem parte das instituições museais por exemplo), e mais qualificável como movimento incorporado pelos indivíduos e comunidades. Todavia, paradoxalmente, a lógica patrimonialista pode, num segundo impulso, reconduzir o movimento aberto a um fechamento, consequentemente à necessidade de acomodar condutas, gestos (associado a alguma técnica, algum ofício etc.) à uma certa formalização. Assim parece sugerir Adell, que lembra, todavia como a própria Convenção tenta ponderações, descartando, entre outras, as exigências de autenticidade e acessibilidade (por exemplo, nos casos de atividades secretas etc.) que não solidarizam com a abertura auspicada.

Finalmente, o novo marco é protagonizado, como bem sugere Adell, "pela participação, em todos os níveis, das comunidades. Elas deixam de ser apenas detentoras e produtoras do seu patrimônio para ocupar também as funções de gestor, promotor e mediador” (2014, p. 31). As 
comunidades quilombolas, sem dúvida vivenciam essas funções, assim como produzem um patrimônio "vivido". Com efeito, aquelas respondem mais ao patrimônio enquanto transformação de culturas - sem aspas - em "culturas" - com aspas - (CARNEIRO DA CUNHA, 2009), a serem valorizadas e vivenciadas, e menos a um patrimônio como ferramenta no qual se "depositam valores" já catalogados como "bons" para serem apreciados (ADELL, 2016, p. 31).

Nessa abertura transformadora, elementos da religiosidade afro-brasileira podem ser muito valiosos para definir os contornos da etnicidade quilombola, já que correspondem a vivências locais e, ao mesmo tempo, a uma linguagem simbólica que pode ser captada para construir uma identidade coletiva feita também pela memória dos tempos sombrios vivenciados pela população negra da região durante o regime escravocrata. Parés (2006) nos conduz ao longo dos séculos XVIII e XIX à descoberta de como, no Recôncavo Baiano, africanos e crioulos criaram, por meio de participação a irmandades, folias, calundus ${ }^{3}$, candomblés, possibilidades de identidades múltiplas, costuradas segundo exigências situacionais e estratégias de resistência e inclusão. A própria ideia de "nação" no Candomblé (nação angola, nagô, jeje etc.) corresponde, segundo Parés (ibidem), mais a um processo de construção de uma identidade étnica e menos a uma consciência de uma procedência geográfica bem definida e comum. De fato, as "nações" correspondem aos termos genéricos, meta-étnicos, cunhados durante o tráfico para nomear escravos de diversas áreas geográficas, que, todavia, apresentavam uma pluralidade de especificidades étnicas.

Considerando as estratégias associadas aos processos identitários evocados por Parés, é legitimo se perguntar se, mutatis mutandis, as dimensões patrimoniais afro-brasileiras dos quilombos poderiam ser pensadas como resistências contemporâneas que demandam também novas estratégias nas costuras das identidades. Dito de outra forma, se, como escreve ainda Adell, o "espírito do patrimônio" é, hoje, tornar visíveis as identidades (2014, p. 38). Neste sentido, a questão que emerge é de buscar compreender como os quilombos de Cachoeira assumem tal exigência construindo sua etnicidade via patrimônio?

Como parte do esforço de responder a essa questão, as contribuições de Meyer (2019) para as relações entre religiões e patrimônio também devem ser consideradas. Por meio do alargamento do conceito de mídia - ao invés de mídia e religião, mídia é religião - e do colapso das distinções entre formas e significados religiosos, a autora redefine novos programas de pesquisa sobre o papel das religiões nas transformações políticas e midiáticas em curso na modernidade. Se a religião é mediação, então precisamos compreender como se processam as relações entre velhas e novas maneiras de veiculação das experiências religiosas. Meyer lança mão do conceito de "formas sensoriais", chamando a atenção para o fato de que os conteúdos, normas e valores religiosos 
não são independentes dos processos de veiculação e de recepção. As "formas sensoriais" seriam a ambiência, as condições de possibilidade por meio das quais se processam os vínculos religiosos entre as pessoas (corporificadas), objetos e não humanos. A partir dessas ideias, Meyer argumenta acerca da necessidade de prestarmos atenção aos processos pelos quais as religiões estão envolvidas nas discussões sobre patrimônio, mediando as produções do que é considerando "autêntico".

Assim, todo processo de resistência cultural implica, evidentemente, em criatividade, como no caso de elementos das religiões afro-brasileiras, associados à ancestralidade, que vão qualificar, para além do espaço do terreiro, um campo étnico-quilombola que se estende pelo território (MARINHO, 2006). Nas discussões que seguem veremos como se inicia essa conexão entre religião e cultura quilombola, assim como ocorrem seus desdobramentos mais recentes nas iniciativas de patrimonialização.

\section{UM TERREIRO NO QUILOMBO}

Nos territórios quilombolas do município de Cachoeira a liderança religiosa afro-brasileira concentra-se sobretudo nas mãos de Geovanda Nery Viana Juvelino, conhecida como Juvani, mãe de santo do terreiro de Umbanda do quilombo Kaonge. Juvani conduz suas atividades litúrgicas tomando como referência as práticas candomblecistas e umbandistas do próprio pai, fundador do terreiro, cujo carisma se encontra fortemente representado em sua narrativa. Ela foi, e continua sendo, mulher de múltiplas funções e papéis sociais. Além de ser mãe de dez filhos, de ter criado outros tantos e de zelar pelo terreiro, Juvani é politicamente engajada e ativa no Conselho Quilombola, liderado por seu irmão Ananias Viana. Ela também foi a primeira professora e diretora da escola local,denominada Escola São Cosme e Damião, provendo o ensino fundamental para muitas crianças da região e mantendo, após a aposentadoria, destacado papel pedagógico na "formação" da cultura local na condição de Mestra Griô ${ }^{4}$.

Sua atuação como Mestra Griô apresenta marcadas características patrimonializantes, podendo ser vista como adesão a uma política da "cultura popular" que se autopromove, impulsionada pelo Plano Setorial para as Culturas Populares, parte integrante do Plano Nacional de Cultura, sancionado pelo Presidente Luís Inácio Lula da Silva, em 02 de dezembro de 2010. Nessa prática, muitas são as narrativas de cunho religioso que Juvani costuma apresentar para os jovens quilombolas, assim como para os visitantes, atraídos pela iniciativa de turismo étnico. Em uma dessas narrativas ela reafirma quea "religião" dos orixás éherança familiar e comunitária. De fato, o seu terreiro de Umbanda é um baluarte da identidade religiosa afro-brasileira para a população de diversos quilombos de Cachoeira. Sobre esta identidade, se lê no laudo antropológico do Kaonge e comunidades próximas: 
A religiosidade de matriz africana está muito presente nas comunidades quilombolas de Caonge, Dendê, Calembá, Engenho da Praia e Engenho da Ponte. A "religião", assim denominada pelos moradores das comunidades, dá significado às práticas cotidianas ligadas ao trabalho e festas. Também está presente nas relações familiares, políticas e sociais que ganham sentido quando associadas a determinados espaços e locais que marcam a trajetória social destes grupos (SILVA; FERNANDES; REIS, 2014, p. 39).

No mesmo laudo é destacado que a "religião" não pode ser dissociada do sincretismo entre umbanda, candomblé e alguns traços do cristianismo. Enfatiza, ainda, a dimensão territorial da "religião", já que uma aliança entre o pai de Juvani e o orixá Xangô e outras "revelações" são evocadas como índices de uma relação identitária com o lugar - uma topofilia:

Falar da comunidade quilombola do Caonge, é contar a história de Zezé Viana, pai de D. Geovanda (Juvani) Viana, atual líder espiritual, matriarca e moradora desta comunidade. Contou D. Geovanda, que a terra onde vive foi "dada por Xangô" a seu pai. Terras estas que marcam épocas distintas da trajetória das comunidades, e são lembradas como o lugar onde acreditava-se que viviam os ex-escravos da antiga Fazenda Campina, um dos locais entendidos como a origem das famílias negras na região e onde a "espiritualidade se revela". Segundo D. Geovanda, 'tudo que se encontra fincado no solo da comunidade do Caonge possui um cuidador espiritual, o que desperta entre os outros moradores o respeito a esse Orixá, que também representa a justiça entre os homens (SILVA; FERNANDES; REIS, 2014, p. 41).

Os eventos da vida de José Viana, muitos dos quais aconteceram quando Juvani não tinha ainda nascido ${ }^{5}$, são apresentados pela filha enfatizando as suas qualidades mediúnicas e a forte ligação entre território, prática religiosa e identidade quilombola. Vale a pena apresentar alguns dos trechos da narrativa de Juvani (em entrevista realizada em 10/03/2017), tanto para considerar aspectos da religiosidade de matriz africana no território, quanto para destacar sua ativação na memória local. Ela enfatiza como os orixás foram coagentes da implantação do terreiro, já que eles obrigaram José Viana a cuidar de coisas de santo lá no quilombo:

Meu pai já morava ali em Acupe [localidade no município de Santo Amaro]. Chega com 22 anos, o que acontece com 22 anos? Tá na hora deles pegarem mesmo, o lugar que chegava pegava, aí ele tinha que aceitar, se tivesse gente precisando de ajuda ele ia lá e tinha que fazer porque eles botava ele pra ir. Era uma mediunidade muito forte! Era uma coisa muito séria!

A história do pai remete, ainda, à perseguição policial, à proteção de Xangô, a um sonho que lhe levou a jogar no bicho e ganhar dinheiro que lhe permitiu comprar um barco. 
Lá no Acupe. O que ele fazia? Ele trabalhava na roça, comprava siri, comprava marisco, levava nos barcos para vender em Salvador, no mercado São Joaquim. Ele tinha muito conhecimento por lá em São Joaquim, você tá entendendo? Então o que que acontece... Um dia foi fazer uma festa para pai Obaluaê, que tem no mês de São Roque, aí fez umas pipocas, começou bater, a cantar, então chega a polícia. Naquela época chega a polícia aí mandou parar a festa. Ele pediu a Xangô, o orixá da cabeça Xangô, e Iemanjá, que desse a ele um dinheiro para ele comprar um barco ninguém mais ia aborrecer a ele, porque o barco dele ia ser a aldeia dele, a casa de morada. Ele teve um sonho e aí ele jogou no bicho, ganhou um dinheiro e comprou um barco... o nome desse barco ele botou Nova Aldeia.

Finalmente o pai de Juvani se enraizou com a família no quilombo Kaonge $^{6}$, construindo, assim, uma memória religiosa, familiar e comunitária. A mediunidade "muito forte", a valentia contra a polícia e a eficácia terapêutica das ações rituais do pai, são rememoradas com gosto por anedota. A reflexividade sobre diversas maneiras de conduzir a "religião" também se fez presente na fala de Juvani, que enfatizou como ela teve que "aprender muito" após a morte do pai, quando era ainda adolescente. Juvani, de fato, tinha resistido por um tempo a assumir a mediunidade herdada do pai, o que lhe provocou transtornos de vários tipos, já que fazia parte de seu destino aceitar a condição de sucessora de seu pai na liderança que viria a dar continuidade por meio de seu próprio terreiro. Finalmente, sob orientação iniciática de uma mãe de santo de Salvador, ela conseguiu se situar na "religião", seguindo o conselho de construir sua própria casa, com seus próprios fundamentos ${ }^{7}$ :

Ela jogou pra mim, aí ela me disse olha aqui não é igual à casa do seu pai, o Xangô daqui, o Ogum... não é igual, não trabalha como seu pai trabalha não, mas vou dar uma ajuda a vocês’. E aí pronto! Ela me explicava como é que fazia as coisas, minha mãe dava o caruru e eu dei continuidade que ela disse que tinha que fazer esse caruru... o santo pediu que eu saísse depois de sete anos da casa que meu pai tinha deixado, que eu tinha que construir era a minha casa, mas era com as telhas que ele deixou, agora o local eu tinha que sair...

É importante destacar a centralidade do caruru, comida votiva à base de quiabo dedicada aos orixás gêmeos (chamados de Ibejis ou Vungi e sincretizados com os santos católicos Cosme e Damião), uma vez que estevai se refletir na culinária e nos rituais da Festa da Ostra, como veremos mais adiante. De fato, o Caruru - a festa para além da iguaria culinária)e outras devoções que mobilizam entidades das religiões afro-brasileiras de forma mais ou menos sincrética, existem e se expandem para além do terreiro de Juvani. Todavia, o Terreiro 21 Aldeias de Mar e Terra permanece como um lugar de expressivo potencial tanto de ativar a memória comunitária inerente à relação do território com uma "ancestralidade", como de promover e fortalecer ações patrimoniais. 
Parece haver uma "marcação de autoridade" (GOW, 2014) na narração de Juvani, já que ela é a filha e testemunha dos fatos protagonizado pelo pai, que foi pessoa de grande importância na "religião" e no quilombo. Acontece também que histórias e mitos contados pelos mais velhos (saberes hoje patrimonializados como mestranças griô) determinam maneiras hierárquicas de se relacionar com o saber. Gow (2014) considera, em relação à narração de mitos e histórias "dos antigos", que, em ambientes tradicionais, os mais jovens geralmente escutam e não se colocam ativamente nas histórias contadas, esperando atingir a etapa da vida em que sejam considerados autorizados a falar. De fato, somente quem tem uma idade mais avançada sente-se à vontade de falar sobre ancestralidade, os mais novos reconhecendo e afirmando que os mais velhos são os detentores dos saberes. No contexto atual, percebemos que filhas e irmãs mais novas de Juvani sempre mostraram um grande respeito pela narrativa da matriarca, cujas conversas sobre o pai, a ancestralidade, a "religião" e a vida antiga no quilombo geralmente não são interrompidas, ela mantendo a palavra de forma quase exclusiva.

Diferentemente de situações nas quais ações patrimoniais acarretam queixas de "perda de autenticidade", em virtude de uma exposição considerada indevida de elementos culturais de valor religioso (assim se pode falar, por exemplo, no contexto patrimonial, de um ritual secreto ou iniciático $)^{8}$, os casos quilombolas parecem ir no sentido contrário para visibilizar exponencialmente o quilombo segundo modalidades de resgate de festas e criações culturais. Como destaca Gonçalves (2012), nesses movimentos observa-se uma transformação nos regimes de autenticidade no patrimônio cultural contemporâneo: da relação com o passado para a transitoriedade da reprodução dos bens culturais.

A Festa da Ostra e outras manifestações religiosas e festivas dos quilombos permitem sair da invisibilidade e, ao mesmo tempo, renovam e reinventam modalidades da cultura quilombola, "fazendo" patrimônio (BASSI; TAVARES, 2017). Embora estruturada como moderno festival gastronômico, a Festa tem como apelo o caruru votivo tradicional; outras festas (Festa de São Roque/Omolu), reeditadas depois de anos de ausência, tornam-se momentos de renovada mitopoiese (com a atuação dos mestres griôs); técnicas terapêuticas (xaropes, notadamente), se fundamentam na sabedoria ancestral e no conhecimento auxiliado pelos caboclos, mas também se recriam como variedades adaptadas ao crescente turismo étnico. Agora o patrimônio é na ação possível, como aponta Varine (2012), um recurso que se encontra em toda parte e que basta procurar para encontrá-lo. Detalhamos, a seguir, cada uma dessas iniciativas. 


\section{A FESTA DE SÃO ROQUE COMO "PONTO DE CULTURA"}

A Festa de São Roque é o mais importante evento do calendário festivo do Engenho da Ponte, além de ser a mais antiga nas comunidades quilombolas dessa região. No relato das pessoas locais esta comemoração foi iniciada nas primeiras décadas do século XX, contudo entre os anos de 1990 e 2000 deixou de acontecer, vindo a ser retomada em 2009 por iniciativa dos moradores do Engenho da Ponte, estimulados pelo então nascente Conselho Quilombola. Desde então vem crescentemente despertando interesse de todos, se tornando momento de intensa sociabilidade entre os residentes e aqueles que, por motivos vários, residem em outras cidades e acorrem ao local para rever parentes e participar de seus vários aspectos.

Como resultado do crescente interesse em revitalizar este destacado evento como parte do ressurgimento identitário quilombola, a edição do ano de 2019 apresentou uma programação significativamente extensa, com duração de três dias - nos anos anteriores a festa concentrou-se no final de semana. A programação teve início numa sexta-feira do mês de fevereiro, com a Roda de Saberes intitulada "religiosidade, resistência e ancestralidade", que ocorreu durante toda a manhã. Os participantes,cerca de duas dezenas de pessoas mais velhas, rememoraram estórias da infância sobre a devoção ao Santo e experiências com "o Velho" - uma das formas de referência a São Roque no legado religioso afrocatólico e ao orixá Omolu ou Obaluayê na memória afro-brasileira, que no imaginário local pode assumir a forma humana, sendo visto e ouvido como parte de uma experiência compartilhada. A certa altura da conversa, Marinalva (que integra o grupo mais dedicado à festa) resume essa confluência com a afirmação (literal, não "simbólica") de que "o São Roque daqui é vivo". Esse clima de devoção contemplativa se estendeu à programação vespertina que realizou o plantio de um baobá ${ }^{9}$ (AdansoniaDigitata) árvore de origem africana, que simboliza a ancestralidade (SANTOS, $2011)^{10}$. Todas as atividades que ali aconteceram foram cercadas de reflexividade. As falas, as disposições e os procedimentos cristalizavam a "autenticidade" da experiência religiosa afro-católica na ancestralidade das famílias que integram àquele território vivido, transmutando seus sentimentos e experiências em patrimônio da cultura local.

Embora com uma ambiência mais afim a de um "Seminário" do que propriamente uma festa religiosa popular, a programação da sexta-feira era investida de forte sentido, já que a festa havia sido recentemente agraciada com uma premiação do governo federal. No ano de 2018, o grupo responsável pela organização da festa resolveu concorrer a um edital do Ministério da Cultura para obtenção de apoio financeiro ${ }^{11}$. A iniciativa foi classificada no $3^{\circ}$ lugar na categoria "cultura popular" entre aquelas que concorreram no Nordeste, além de ser reconhecida como "ponto de cultura" (projetos financiados e apoiados pelo gover- 
no federal). O "coletivo cultural" - grupo envolvido com a organização e continuidade da festa - teve sua iniciativa "Devoção Quilombola a São Roque: Esmola Cantada, Procissão e Festa" reconhecida como importante elemento para o fortalecimento da cultura local, articulando a promoção de direitos, cidadania e diversidade cultural. Essa iniciativa de concorrer ao edital contou com o nosso apoio enquanto pesquisadores-parceiros dessas comunidades, já que o processo de inscrição requeria esforços variados: a) a formulação do projeto que, no caso, fundamentava a conexão da festa com o fortalecimento da cultura local (com o qual estivemos mais envolvidos), b) o recolhimento de assinaturas e, c) a "comprovação" da existência da festa, recolhendo, fotos, vídeos e outros documentos, entre estes, um artigo sobre a festa(BASSI; TAVARES, 2017).O reconhecimento da nossa colaboração se deu ao final daquela "Roda" da manhã de sexta-feira, quando Selma e Bárbara, mãe e filha, nos presentearam com um pequeno quadro que retrata São Roque, distinção que foi conferida para os poucos reconhecidamente envolvidos com a devoção local.

O Engenho da Ponte é um dos quilombos que integram o Conselho Quilombola. A festa de São Roque compreende um conjunto de atividades que se iniciam no mês de janeiro com a esmola cantada, período preparatório da festa, sempre aos domingos. A festa propriamente dita ocorre num final de semana de fevereiro ${ }^{12}$, em data móvel, sempre coincidente com os finais de semana.

A confluência de uma história ("factual") e de uma experiência religiosa afro-católica se expressa na própria origem da festa, remetendo a acontecimentos que marcaram profundamente a comunidade do Engenho da Ponte, decorrente de atos de devoção relacionados a surtos de varíola, sarampo e catapora, ainda no início do século XX. Nessa comunidade existe uma árvore, gameleira (Ficus Adhatodifolia), e um poço de água curativa, local conhecido pelo nome de "Pé do Velho", em torno do qual os negros escravizados se reuniam para fazer suas orações, oferendas e outras obrigações rituais. Muitas festas, narrativas e histórias de São Roque sincretizam os arquétipos do santo católico com o orixá Omolu ou Obaluayê, associado à terra, às epidemias e doenças da pele. A devoção ao São Roque mistura-se com a devoção ao "Velho", como o chamam, em sintonia não apenas (ou não exatamente) com a cosmologia sincrética que associa os santos aos orixás, marcando a religiosidade afro-católica nas experiências da devoção popular. Pode-se dizer que essa identificação é vivida não como referente cosmológico, generalizado e abstrato, mas como experiência corporificada sui generis (afinal a presença do Velho é testemunhada por reiterados relatos), marcada pela ancestralidade - física e espiritual - e estendida aos viventes daquela comunidade e de outras próximas.

A festa de São Roque tem sua origem relacionadaao já mencionado evento histórico das primeiras décadas do século passado - as mortes de 
crianças e adultos provocada pelas epidemias na região -, determinando tanto o ato de narrar "histórias dos antigos" (uma mitopoiese, como define Gow, 2014), quanto uma ação devocional, isto é, uma "promessa". Existe uma "história dos antigos", contada pelos moradores do Engenho da Ponte, que diz respeito ao mês de agosto (mês de Omolu/Obaluayê), momento em que aparecia no quilombo um velho descalço andando lentamente pela comunidade com um saco de linhagem, uma cabaça na costa e uma cuia na mão pedindo esmola nas casas. A grande mortandade devida às epidemias fez com que as pessoas reconhecessem naquela experiência a corporificação do próprio Velho, isto é, o orixá Omolu/ Obaluayê. Os moradores do quilombo daquela época se reuniram então no local de difícil acesso demarcado pela mencionada árvore, no qual a presença do "Velho" era frequentemente sentida e se corporificava, daí ser reconhecido e denominado "Pé do Velho". Na ocasião, eles fizeram uma promessa à São Roque de realizar a festa anual em seu louvor em troca do fim das doenças e mortalidade decorrente destas.

A narração sobre o Velho andando descalço pelo quilombo diz menos respeito à constituição simbólica da "religião" e mais enquanto gatilho para ação social. Pensamos aqui na narração dos mitos e das histórias dos antigos como "mundo vivido", mobilizador de ações (GOW, 2014, p. 187). Em geral, para além do seu conteúdo simbólico, as narrações se conectam com as motivações para ouvi-las e contá-las (ver GOW, 2014). Se na época das epidemias o "mito de velho descalço" foi mobilizador de ação (a promessa e a implementação da festa), contemporaneamente a conexão da festa de São Roque com Omolu/Obaluayê e as relativas narrações confirmam o envolvimento na "religião". Mas, sobretudo, permanece e resgata-se com os griôs o interesse pelas histórias contadas enquanto momento de identificação com a própria origem, uma vez que foram os mais antigos que as contaram para os mais novos, a narração fazendo recuar no tempo e nas gerações e estabelecendo o elo parental e comunitário.

Nessa época da feitura da promessa ao Santo, a proprietária da fazenda era católica, muito devota de Nossa Senhora da Conceição, para a qual promovia festejos na capela da localidade na data dedicada à santa, no dia 8 de dezembro. Ela entregou à comunidade uma imagem de São Roque, no intuito de promover sua devoção entre os membros da comunidade. Anos depois, em decorrência das dificuldades de realização da festa no mês de agosto (época chuvosa e o solo de massapê dificultavam a locomoção), esta passou a ser realizada no mês de fevereiro, com a "anuência" de São Roque. A imagem do santo católico é, em várias casas dos moradores, homenageada em altares domésticos com oferendas de pipoca, o que, em definitivo, nos faz passar de uma iconografia católica aos artefatos (oferendas associadas à culinária, contas etc.) da religiosidade afro-brasileira, indicando também seu existir e resistir. 
Foi durante um Encontro de Mestres e Aprendizes Griôs do "Projeto Bagagem”, realizado em Lençóis (BA), em 2008, que a própria Juvani determinou, a partir de um sonho que ela teve, a importância de uma revitalização da Festa de São Roque por meio da esmola cantada. A retomada da devoção a São Roque e a sua implícita patrimonialização se apresentam, assim, como induzidas pela reflexão sobre a importância da "religião", das devoções e da história contada, esta última apresentando detalhes que espelham as ações atuais da festa com a narração mítica (a própria esmola está contemplada na história do Velho descalço). Outrora os negros escravizados conseguiam, graças às histórias contadas, promover uma vida comunitária relacionada com a origem em comum. $\mathrm{Na}$ atualidade, a patrimonialização da oralidade por meio dos "griôs" resgata vivências da "religião" e da cultura quilombola, promovendo também o fortalecimento das identidades quilombolas.

A festa de São Roque é importante não apenas para o Engenho da Ponte, mas também para as outras comunidades próximas, pois a esmola cantada circula pelo amplo território quilombola do Iguape, distrito de Cachoeira. Assim, nos domingos do mês de janeiro, diferentes comunidades participam do peditório, tendo sempre a participação e liderança do grupo do Engenho da Ponte que percorre grandes distâncias e transpõe obstáculos sob o sol escaldante do verão, a pé ou de ônibus, pelas estradas de barro e de asfalto que cortam a região.

Na esmola cantada, o grupo precursor é constituído pelos musicistas e cantadores de ambos os sexos, tocam pandeiros, cavaquinhos e tambores. Esse grupo inicia sua jornada bem cedo pela manhã, sempre saindo da casa do(a) dono(a) da "bandeira de São Roque" (o/a) responsável), no Engenho da Ponte. Uma parada em cada casa no caminho os espera por todo o dia, seja qual for a comunidade escalada para a visita. No primeiro domingo da esmola cantada o trajeto se inicia no Engenho da Ponte, sendo a primeira visita do grupo ao Pé do Velho, onde são entoados os cantos devocionais que integram o patrimônio cultural local, que são mantidos pela memória de pessoas reconhecidas como guardiãs daqueles cantos, destacando-se a liderança de João Abade e composição do grupo musical majoritariamente de seus familiares.

Depois dos vários domingos de esmola cantada, a festa acontece num final de semana do mês de fevereiro (à exceção do ocorrido em 2019, conforme mencionado acima). No sábado à noite dá-se início aos festejos com a apresentação de vários grupos musicais (de samba de roda, dentre outros estilos musicais), danças, comercialização de produtos locais e comidas típicas. No intervalo do baile dançante, pode-se também participar do leilão que é realizado para arrecadação de fundos. No domingo pela manhã tem lugar a missa solene e batizados de crianças, com o padre especialmente convidado para a ocasião. Após a missa segue o grande almoço oferecido a todos os participantes, atualmente conta com cerca de trezentas pessoas provenientes de várias comunida- 
des, incluindo algumas que residem em outros municípios e comparecem regularmente na ocasião. Merece ser ressaltada a importância do trabalho cooperativo da parte da rede de solidariedade, que se materializa no preparo, arrumação e decoração da igreja, no receptivo para a refeição e na organização e condução da procissão em seguida ao almoço.

À tarde, é a vez de sair da igreja em procissão, quando as imagens de Nossa Senhora da Conceição e de São Roque são levadas em seus andores pelo percurso tradicional que atravessa toda a extensão da comunidade, devendo-se notar que a participação é preponderantemente feminina. As rezadeiras da procissão vão à frente do cortejo puxando as rezas próprias desta celebração. Muitas delas costumam cobrir a cabeça com o torço, que constitui um indicador visível de uma adesão à "religião". É importante enfatizar que o patrimônio imaterial constituído pelos cantos, sonoridades, ritmos e orações constitui parte fundamental desses momentos solenes que compõem essa formação sensorial, como apontado por Meyer (2019).

\section{ROTA DA LIBERDADE: TERRITÓRIO, PATRIMÔNIO E TURISMO ÉTNICO}

A exemplo de outras iniciativas voltadas para a visibilização e promoção comercial do patrimônio étnico-cultural por meio da visitação como fator gerador de renda, a denominada Rota da Liberdade constitui uma destacada iniciativa da parte das comunidades quilombolas do Iguape, que promovem as visitas que oportunizam o compartilhamento de experiências com pessoas de várias procedências e interesses em conhecer o diversificado patrimônio cultural disponível na área e a vida nos quilombos contemporâneos.

Para melhor compreender esta e outras iniciativas semelhantes, é importante considerar a visão dos cientistas sociais, antropólogos em especial, que têm se dedicado ao estudo do turismo e seus impactos e efeitos, tanto positivos quanto negativos, sobre pequenas comunidades e, particularmente daqueles que decorrem das relações entre nativos e visitantes (GREENWOOD, 1972, 1976; OLIVER-SMITH; CAROSO e RODRIGUES, 1998; ARRONES e ARCAL, 1989; SMITH, 2012 [1989]; GRÜNEWALD, 2003). Estes reconhecem que as interferências sobre as culturas e, muitas vezes, a perda de autenticidade das culturas locais é um fantasma que ronda as iniciativas de turismo junto às populações tradicionais. Nas últimas décadas, os esforços têm se mobilizado em torno do chamado turismo étnico, em suas modalidades de "nicho" de mercado e de base comunitária, contudo os pesquisadores chamam a atenção para os limites do turismo étnico de mercado, que fomentam a espetacularização e exotização dos símbolos religiosos (VATIN, 2008; CARVALHO; AVILA, 2012). 
Outro caminho tem sido o do turismo de base comunitária, marcado por maior autonomia (BARTHOLO; SANSOLO; BURSZTYN, 2009), sendo essa a inspiração para o turismo étnico da Rota da Liberdade, organizado pelas comunidades do Kaonge, Dendê, Kalembá, Engenho da Ponte e Santiago do Iguape. Assim, a busca por modalidades alternativas de turismo evidencia as ambiguidades da relação entre bens inalienáveis e mercado nas experiências contemporâneas do patrimônio cultural (GONÇALVES, 2007).

Desde o início dos anos de 2000 essas comunidades se encontram envolvidas em atividades de mobilização cultural, especialmente projetos de dança. Em 2002, fundaram o Centro de Educação e Cultura Vale do Iguape (CECVI), organização local que vem se mostrando de fundamental importância na viabilização do movimento quilombola. Com a implantação do Conselho Quilombola da Bacia e Vale do Iguape, em 2005, as formas de organização das comunidades expandiram-se por meio dos núcleos de produção, buscando garantir a permanência das famílias no território num regime de economia solidária. $O$ turismo étnico veio a surgir nesse contexto, como um núcleo de etno-desenvolvimento (BORBA, 2018).

Embora tenha sido implementado a partir de 2005, a inspiração inicial da Rota da Liberdade é anterior à formação do Conselho Quilombola, decorrendo da participação das comunidades no Edital "Cultura Viva” - de Pontos de Cultura - do governo federal (novamente a participação de editais de fomento na produção de cultura), que possibilitou a seleção de 20 jovens para realizar um mapeamento do potencial do território para implantação de projetos (BORBA, 2018). Essa experiência resultou num "redescobrimento" das narrativas históricas pelos jovens, produzindo novas nervuras num espaço altamente significativo para essas comunidades (SANTOS, 1994), num contexto social e político de intensa ressemantização da condição quilombola (ARRUTI, 2008). Conforme apontamos em trabalho anterior (CAROSO; TAVARES; BASSI, 2018, p. 45), a ativação da cultura como patrimônio promovida pela Rota da Liberdade contrabalança e tensiona as vulnerabilidades do patrimônio quilombola, um passado que também se quer esquecer.

A pouca atenção e cuidado com os sinais e pistas sobre o passado, tanto da vida dos negros escravizados quanto das elites brancas, pode ser constatado por meio de prospecção visual pelo território em companhia daqueles que conhecem e reconhecem seus lugares de memória: os traçados e estruturas das antigas fazendas, engenhos, residências e alguns monumentos que gradativamente se tornam parcos vestígios de difícil identificação em consequência da deterioração, o que os leva a correr o risco de total desaparecimento na paisagem arqueológica da região [...] (CAROSO; TAVARES; BASSI, 2018, p. 45).

A Rota da Liberdade faz circular o patrimônio cultural das comunidades, tanto para dentro do território, por meio dos pacotes de visita- 
ção, e de percursos pelas comunidades como a "Caminhada Ancestrais" (que rememora os antigos percursos para vender os produtos locais em outras localidades); quanto para fora, em feiras e exposições em Salvador e outras cidades. Aos visitantes que chegam, são oferecidos produtos combinados às experiências. Assim, pode-se adquirir farinha de mandioca, azeite de dendê orgânico (um produto diferenciado, acrescido de ervas aromáticas), mel, peças de artesanato e o famoso "xarope de Vardé". Combinando-se aos produtos, temos as experiências da degustação de ostra (pode-se apreciá-la em pratos variados no restaurante "É d'Oxum", no Kaonge), das rezas oferecidas por Juvani, Vardé ou Pina (conforme a disponibilidade das mulheres e o tamanho do grupo de visitantes), das histórias dos antepassados contadas por Juvani, da visita ao quintal das ervas medicinais de Vardé e a observação de fragmentos do processo de feitura do xarope. Os processos de feitura artesanal do azeite de dendê e da farinha também são apresentados aos visitantes. Além dessas atividades que tem lugar no Kaonge, pode-se conhecer o núcleo de ostreicultura, na comunidade do Dendê; visitar belíssimos sítios arquitetônicos (capelas, igrejas e o Convento de São Francisco do Paraguaçu) e arqueológicos (vestígios dos antigos engenhos).

Enfim, produtos, pacotes de visitação, experiências, vestimentas e performances que resultam dos esforços daqueles envolvidos na Rota da Liberdade, mas também de agências não humanas, como a entidade indígena (Cabocla) de Vardé - da família espiritual do Terreiro de Umbanda 21 Aldeias de Mar e Terra, sob a liderança de Juvani -, que ofereceu a receita do xarope especialmente para fortalecer essa iniciativa. A produção do xarope surge como uma "receita de resistência", no sentido apresentado por Sztutman (2018, a partir de uma inspiração de Isabelle Stengers), posteriormente desenvolvido em Pissolato (s/d), que produz a conexão com a experiência de Vardé.

De fato, como vimos no início deste artigo, o território é perpassado pela religiosidade afro-brasileira, já que os orixás se conectam com vivências dos ancestrais, heranças de santo e fundamentos religiosos territorializados. No caso dos quilombos, trata-se de uma territorialização menos evidente em comparação àquela dos candomblés tradicionais da região, todavia, esta reproduz formas do "mundo vivido", caras à maneira quilombola de "fazer comunidade" a partir de ontologias próprias. As ervas medicinais e as agências interespecíficas a estas associadas são importantes conectores dessas ontologias afro-religiosas que se espraiam no território e que também estiveram implicadas nos esforços mais recentes de "colecionamento" (GONÇALVES, 2003), para sua transformação em "patrimônio terapêutico", como veremos a seguir. 


\section{MAPEAMENTO DOS PRATICANTES TERAPÊUTICOS}

Apesar do processo de territorialização da biomedicina promovida pela ESF (Estratégia de Saúde da Família - política de atenção básica do governo federal), despontam movimentos que buscam revitalizar as tradições terapêuticas de referências afro-religiosas, dentre outras como redes intersticiais (BONET; TAVARES, 2006). No Kaonge presenciamos nos últimos anos uma revitalização do aprendizado em ação (pessoas tornando-se rezadores). Ao longo de nossas pesquisas nas comunidades observamos processos ambíguos: se por um lado, existe de fato a preocupação com a perda dos conhecimentos das ervas; por outro, as práticas continuam presentes no cotidiano e contam com iniciativas para sua valorização (ervas, chás, xaropes, remédios e rezas) como patrimônio terapêutico quilombola.

Assim, a preocupação com a vulnerabilidade dessas formas de cuidado, compreendidas como "cultura" dos antepassados, desencadeou a realização de um mapeamento dos saberes e práticas terapêuticas, que inicialmente compreendeu uma parceria entre pesquisadores da Universidade Federal do Recôncavo Baiano (UFRB) e a ONG italiana COSPE, com Vanderson dos Santos e Rosângela Jovelino, moradores do Kaonge, e com a inclusão do nosso grupo de pesquisa (ObservaBaía/Universidade Federal da Bahia - UFBA) na coordenação dessa iniciativa.

O objetivo inicial do mapeamento era de localizar as pessoas socialmente reconhecidas nesse ofício, tarefa que se mostrou mais complexa que pensávamos. Por um lado, identificávamos poucas rezadeiras, raizeiros e outros "especialistas". Por outro lado, muitos pareciam ser bem familiarizados com esses cuidados em suas vidas cotidianas. Essas "diferenças" nos levaram a compreender essas formas de circulação descentralizada por meio do conceito de "praticantes terapêuticos", afastando-se assim do bias de demarcações precisas evocadas na noção de "especialistas". Com essa compreensão "afrouxada", fomos seguindo as pistas indicadas por aqueles que havíamos entrevistado, vindo a resultar na identificação de 63 pessoas diretamente apontadas como "praticantes", sendo que visitamos e entrevistamos 42 delas $^{13}$.

Em dezembro de 2017, quando ainda estávamos realizando as entrevistas, ocorreu uma reunião dos pesquisadores com os representantes do Conselho Quilombola, no quilombo Engenho da Ponte, para avaliação das parcerias em curso e, mais especificamente, do mapeamento. Nossa conceituação dos praticantes terapêuticos foi apresentada, não gerando controvérsias. O ponto de maior interesse das lideranças referia-se às formas de publicização dos resultados, que era desejada em sua integralidade. $\mathrm{O}$ foco seriam os praticantes terapêuticos, sem anonimato, nem informações selecionadas: o pleito quilombola combinava intenções de registro, resgate, reconhecimento e acesso para as comunidades. Assim, a primeira edição do mapeamento foi um pequeno livro que priorizou 
a apresentação dos praticantes terapêuticos em imagens e fragmentos de suas histórias de vida, combinada à relação das plantas medicinais mais utilizadas nas comunidades, com imagem e desenho. Esta edição do livro teve seu lançamento durante a X Festa da Ostra, em outubro de 2018, ao mesmo tempo em que ocorreu a exposição fotográfica apresentada como parte da programação daquele evento, os praticantes terapêuticos puderam se ver nas belas imagens do livro e reconhecer-se uns aos outros nesse processo de construir um patrimônio terapêutico local, assim como compartilhar suas experiências.

Associada à publicação, seria disponibilizado em edição eletrônica o Dossiê completo da pesquisa, iniciativa que foi substituída pela realização de uma segunda edição publicada pela Edufba (TAVARES; CAROSO; BASSI, PENAFORTE; MORAIS, 2019).No livro buscamos apresentar a diversidade dos praticantes terapêuticos, das ervas, rezas e outros elementos não em termos do reconhecimento das qualidades fitoterápicas, garantidas pelos princípios ativos das plantas, como visibilizadas nas abordagens das etnociências. Seguindo as observações de Oliveira (2012, p. 19), a compreensão dos conhecimentos tradicionais não pode ser feita tendo como "fundo silencioso" as classificações etnobotânicas, que surgem como um parâmetro para a classificação dos praticantes terapêuticos quilombolas. Afinal, sempre haverá algum ônus nas "passagens" de um sistema a outro, mas as "ausências" de correspondência de ervas e taxonomias científicas ou as diferenças nos usos terapêuticos não podem ser relegadas à vala comum das "crenças populares".

As ervas e outros elementos estão implicados nas "palavras", nas rezas, que podem afastar ou atrair energias, fechar corpos. É preciso ter cuidado com as palavras, que combinam observância e inventividade: pode-se rezar baixinho, para que ninguém ouça, ou falar em voz alta as palavras aprendidas; pode-se deixar vir do coração pequenas diferenças nas palavras, ou até novas palavras e novas rezas. Em todas as possibilidades, são as palavras das rezas e das lembranças e esquecimentos que precisam ser cuidadas em sua potência num mundo que, como sugere Sauma (2016, p. 150), “[...] as palavras já são coisas que adentram a carne, o corpo, a pessoa, transformando-na”.

Constata-se, de fato, que nas ontologias religiosas afrocatólicas dos quilombos, mobilizadas por Vardé, Juvani e muitas rezadoras e rezadores apresentados nesse mapeamento, cuja vocação terapêutica é incisiva, materiais diversos se misturam com rezas, preces, evocações de poderes especiais dos santos católicos ou entidades de matriz africana etc. Assim, não é fácil, nem oportuno, entender os limites dos efeitos terapêuticos das garrafadas e início da eficácia da "fé". A eficácia de ordem simbólica (TAVARES; BASSI, 2013), mobilizada pelo ritualismo inerente às curas religiosas parece operar uma mediação entre processos vitais e processos técnicos. Etnografias diversas apontam para a relevância da ação técnica e dos artefatos em geral (que podem assumir valores simbólicos) 
na compreensão da complexidade da vida, assim que os próprios artefatos, os símbolos implícitos e os processos naturais seriam pensados mutuamente (PITROU, 2015). Neste sentido, a patrimonialização das terapêuticas tradicionais pode ser pensada como patrimonialização de uma "etnoteoria" abrangente.

\section{FESTA DA OSTRA: INVENTIVIDADE ESTÉTICA DO PATRIMÔNIO QUILOMBOLA}

Em 2009, teve lugar a primeira edição da Festa da Ostra, que desde então se tornou um evento anual ininterrupto no quilombo Kaonge, com a venda de produtos, rodas de conversa, samba de roda e culinária, fazendo circular e visibilizando a cultura quilombolas dessas comunidades. Novas atividades são introduzidas a cada edição da Festa: os núcleos de produção ${ }^{14}$ têm participado da Festa na forma de "oficinas" aberta aos visitantes (artesanato, Rota da Liberdade, azeite de dendê, ostreicultura e apicultura, culinária/gastronomia entre outras).

A festa é também marcada por celebrações de cunho ritualístico e devocional: são homenageados os orixás com cantigas e ocorre a preparação do tradicional caruru. O caruru, iguaria preparada com quiabos, é ofertado aos santos Cosme de Damião, sincretizados com os orixás Ibejis. Para além da dimensão moderna do festival de gastronomia, a festa é uma maneira de patrimonializar um ajeum. Nas palavras de Juvani: "Ajeum é o termo iorubá destinado às refeições. Sua tradução mais literal é "banquete" e constitui o ato de comer e dar de comer às entidades pelos seguidores dos cultos afro-brasileiros" (Depoimento disponível no site do CECVI).

Desde 2015 temos presenciado a abertura do evento, que conta com uma performance político-festiva em que são apresentadas às autoridades presentes as demandas por direitos expressos na "carta quilombola" (iniciativa da qual participamos desde sua primeira ocorrência). Ao longo destes últimos cinco anos, temos observado que os agentes buscam criar, recriar, inovar suas demandas e formas de apresentá-las, o que veio mais clara e criativamente ocorrer na edição da Festa da Ostra de 2019, o tema intitulado "Guerreiros quilombolas em sonho de liberdade" foi apresentado pelas lideranças do Kaonge, enfatizando a importância da arte para a cultura quilombola local, assinalando que foi por meio da arte que tudo começou ${ }^{15}$. Assim, antes da fala de convidados (autoridades políticas, gestores acadêmicos dentre outros) assistimos a uma performance (com quase cerca de uma hora de duração) que mesclava danças de inspiração afro-reggae com tambores, marcações corporais e indumentária, em que se desencadeava uma batalha entre forças da vida e da morte, pontuadas pela ação de um medicine man/terapeuta tradicional, que, usando recursos naturais e manipulação simbólica de 
corpos, devolvia a vida aos guerreiros abatidos. Estava em curso novas experimentações estéticas (MEYER, 2019) das reconhecidas conexões entre religião, arte, política e etnicidade, marcas da Festa da Ostra.

Assim, mais do que "expressar" ou "representar" a cultura, a Festa da Ostra propicia o espaço e estimula a inventividade estética dos modos de fazer e viver quilombolas. Como sugerem Bassi e Tavares (2017), a Festa da Ostra "pode ser compreendida tanto a partir do conceito de "tradição inventada" (HOBSBAWM; RANGER, 1982), quanto a partir das contribuições de Wagner (2010) sobre inventividade inerente aos processos de simbolização da cultura.

\section{CONCLUSÃO}

Como já alertava Gonçalves (2003), as ambiguidades em torno do conceito de patrimônio colocam em movimento diferentes concepções nativas de lideranças políticas, religiosas, dos leigos e moradores das comunidades em geral, dos gestores e especialistas. Iniciativas gestadas entre nossos interlocutores não parecem amenizar os desdobramentos e controvérsias dessas criações, já que, num sentido muito preciso, mais que sinais diacríticos, a patrimonialização evoca formas de autoconsciência cultural (GONÇALVES, 2003, p. 32).

As iniciativas de um pequeno grupo de comunidades estendem seus efeitos por toda a região da Bacia e Vale do Iguape, a despeito de importantes diferenças, entre as comunidades, das condições de vida (demografia, acesso à terra, água, transporte, saúde etc.) e de sociabilidade (especialmente o avanço das igrejas pentecostais vem transformando costumes, práticas festivas e de lazer, formas de cuidado etc.). O patrimônio afro-religioso mobilizado pelas comunidades do Kaonge, Kalembá, Dendê, Engenho da Ponte e Engenho da Praia, por meio das iniciativas apresentadas, vem "formatando" uma nova estética e, paralelamente a cultura das comunidades vinculadas ao Conselho Quilombola. Existem terreiros de candomblé em comunidades mais distantes vinculadas a esse movimento (Engenho da Vitória, Acutinga-Mutecho, Terra Vermelha), compreendendo um patrimônio comum, reconhecido pelos quilombolas da região, mas configuram experiências localizadas, não visibilizadas como cultura quilombola no mesmo "estilo" que a do grupo articulado em torno do Kaonge.

Por outro lado, parece-nos que o processo bem-sucedido de dinamização estética, midiática e patrimonializada da cultura quilombola se deve à conexão entre vínculos religiosos afro-católicos (a família do Terreiro liderado por Juvani, que se estende à comunidades referidas), de parentesco (os moradores do Kaonge constituem uma família extensa) e de território (compartilhamento do mesmo projeto político-cultural nessas comunidades). 
Vimos que o processo de etnicização da cultura, transformado por iniciativas e demandas de patrimonialização da cultura afro-religiosa dissemina-se em muitas direções, produzindo conexões entre dimensões oníricas, de não humanos e do trabalho na revitalização da festa de São Roque (da agência do Velho), na Rota da Liberdade (na receita do xarope de Vardé), no patrimônio terapêutico, nas performances que integram e constituem a Festa da Ostra. Se a identidade quilombola e a luta por novos direitos não são circunscritos exclusivamente às experiências políticas da etnicidade (MELLO, 2012), é preciso levar a sério essas conexões que nos ajudam a entender a radicalidade do projeto contracolonizador, conforme destacado por Antonio Bispo dos Santos, ativista quilombola, em sua capacidade de ressignificar a vida em "[...] territórios retalhados, descaracterizados e degradados" (SANTOS, 2015, p. 97).

\section{NOTAS}

1. Kaonge, Kalembá, Kaimbongo Velho, Kalolé, Dendê, Engenho da Ponte, Engenho da Praia, Imbiara, Tombo/Palmeira, Engenho da Vitória, Engenho Novo, Engenho da Cruz, Brejo da Guaiba, Mutecho/Acutinga e Terra Vermelha, sendo as duas últimas em processo de certificação.

2. A primeira "Carta Quilombola", para elaboração da qual nos foi solicitado apoio, se deu em data antecedente à VI Festa da Ostra do ano de 2016, sendo aquela lida diante das autoridades governamentais presentes, seguida de entrega de cópia impressa a cada um deles no momento de abertura oficial do evento. Desde então as Cartas se tornaram parte integrante da ocasião, ocorrendo ainda a elaboração de uma Carta Quilombola estadual no ano de 2019, para a qual nossa participação na elaboração também foi solicitada.

3. Cultos de matriz africana típicos do Brasil Colônia. Não tinham ainda templos propriamente ditos, mas, locais consagrados às suas práticas espirituais.

4. A categoria social "Griô surge como uma metáfora da memória e ancestralidade do povo brasileiro, memória viva de povos que não se calaram e mantiveram vivas suas tradições e identidades em comunidades de re-existência". (GRÃOS DE LUZ E GRIÔ, 2020). No que se refere ao uso, significado e papel de mediadores que exercem os Griôs, Silva (2012, p. 60) destaca que: "O termo Griô é uma adaptação para a língua portuguesa do termo francês Griot, que designa os agentes culturais da tradição oral africana que atuam como cronistas, genealogistas, cantores, contadores de histórias, poetas, mestres de cerimônias, entre outras formas de mediação, responsáveis pela transmissão dos saberes para os membros de suas comunidades."

5. Essa época, antes do nascimento de Juvani, corresponda aos anos 1940.

6. Chamado de "macumbeiro" pelo sogro, José Viana transitou também pelo kardecismo, a adesão a este último condicionando a alteração do nome do terreiro de Umbanda, por um tempo. Sobre o nome do terreiro, Juvani explica: "21 Aldeias de Mar e Terra e depois ele botou Casa de Oração 21 Aldeias de Mar e Terra. Porque é assim, ele começou com umbanda, entendeu? Na umbanda arrumava confusão e depois ele achou que tinha que ser kardecista.... 
7. A prática de Juvani poderia ser interpretada como "umbanda popular", mantendo uma certa precaução na atribuição de denominações. Aqui tomamos como referência a definição encontrada em um site especializado na internet: "Podemos definir genericamente a Umbanda Popular como, uma das práticas existentes na religião que não segue um determinado "chefe" ou "líder" percursor, tampouco um conjunto literário de base, definidores dos princípios doutrinários e ritualísticos, ou seja, cada grupamento que se engloba neste cenário geralmente é liderado pelo próprio "Guia Chefe do Terreiro" (entidade espiritual), seguindo tendências bem particulares sem qualquer vínculo com outros movimentos" (MUNDO DAS UMBANDAS, 2020).

8. Sobre essa questão, ver Adell (2016).

9. O plantio foi realizado no terreno dos fundos da igreja, sendo a muda doada por um professor da UFRB que mantem um viveiro de mudas em sua casa com o propósito fazer destas demarcadores de etnicidade afro-brasileira.

10. Árvore gentilmente doada pelo professor Cláudio Orlando, da UFRB.

11. Edital de Seleção Pública No 01, de 26 de abril de 2018. Culturas Populares: Edição Selma do Coco.

12. Vale notar que esta antecipação da data comemorativa que regularmente ocorre no mês de agosto se deve às condições de acesso do padre ao local naquela época chuvosa, o que levou à redefinição da temporalidade da comemoração.

13. O mapeamento foi estendido às 17 comunidades da região, incluindo, portanto, duas comunidades não participantes do Conselho.

14. Nos territórios quilombolas articulam-se núcleos de produção comunitária (cultivo de ostras, farinha de mandioca, apicultura, artesanato), economia (Banco Solidário Quilombola do Iguape, com a moeda social denominada "Sururu"), de sustentabilidade socioambiental, tradições culturais (samba de roda, danças afro etc.), festivais e iniciativas educativas (conduzidas pelo CEVCI-Centro de Educação e Cultura do Vale do Iguape), além de projetos e parcerias com ONGs, universidades e organizações várias, buscando o fortalecimento da cidadania na luta por políticas públicas inclusivas.

15. O início do movimento quilombola aproximou jovens do Kaonge e de Santiago do Iguape em torno de uma companhia de dança. Posteriormente essas comunidades receberam um projeto de extensão da UFBA, focado em educação, coordenado pelo então Reitor Felipe Serpa, que potencializou os esforços incipientes dessa $1^{\text {a }}$ geração de ativistas quilombolas. O CECVI - Centro de Cultura do Vale do Iguape foi a primeira organização quilombola da região.

\section{REFERÊNCIAS}

ADELL, Patrick. Os giros do patrimônio. In: CAVIGNAC, Julie; MACÊDO, Muirakytan K. de. (Orgs.). Tronco, ramos e raízes! História e patrimônio cultural do Seridó negro. Natal: EDUFRN, 2016. p. 19-47

ANJOS, Jose Carlos G. dos. No território da linha cruzada: a cosmopolítica afro-brasileira. Porto Alegre: Editora da UFRGS/Fundação Cultural Palmares, 2006. 
ARRUTI, José Maurício. Quilombos. In: SANSONE, Lívio; PINHO, Osmundo (Orgs.). Raça: novas perspectivas antropológicas. Salvador: ABA/ Edufba, 2008. p. 315-350.

BARTHOLO, Roberto; SANSOLO, Davis G.; BURSZTYN, Ivan (Orgs.). Turismo de base comunitária: diversidade de olhares e experiências brasileiras. Rio de Janeiro: Letra e Imagem, 2009.

BASSI, Francesca; TAVARES, Fátima. Preparando o banquete, sonhando a festa: memória e patrimônio nas festas quilombolas (Cachoeira-Bahia). Aceno: revista de Antropologia do Centro-Oeste, v. 7, n. 4, p. 15-32, 2017.

BONET, O. A. R.; TAVARES, F. R. G. Redes em redes: dimensões intersticiais no sistema de cuidados à saúde. In: PINHEIRO, R.; MATTOS, R. A.(Orgs.). Gestão em redes: práticas de avaliação, formação e participação na saúde. Rio de Janeiro: CEPESQ, 2006. p. 385-399.

BORBA, M. Rota da liberdade: turismo étnico nos quilombos da Bacia e Vale do Iguape, Cachoeira, Bahia. Trabalho de Conclusão de Curso (Bacharelado em Ciências Sociais) - Salvador, UFBA, 2018.

CAPONE, Stefania; MORAIS, Mariana R. de. De la négation à l'affirmation: le processusd'institutionnalisation du patrimoine culturel afro-brésilien. Afro-patrimoines Culture afro-brésilienne et dynamiques patrimoniales: les Carnets Du Lahic, n. 11, p. 6-24, 2015.

CARNEIRO DA CUNHA, Manuela. Cultura com aspas e outros ensaios. São Paulo: Cosac Naify, 2009.

CAROSO, Carlos; RODRIGUES, Núbia. Nativos, Veranistas e Turistas: identidade, mudança e deslocamento sociocultural no Litoral Norte da Bahia. Turismo em análise, São Paulo, v. 1, n. 9, p. 61-75, mai. 1998.

CAROSO, Carlos; TAVARES, Fátima; BASSI, Francesca. Paisagens, memória e identidade: vulnerabilidade socioambiental do patrimônio cultural quilombola. Acesso Livre, n. 9, p. 41-60, jan./jun. 2018.

CARVALHO, Ana Paula Comin de. Tecnologias de Governo, Regularização de Territórios Quilombolas, Conflitos e Respostas Estatais. Horizontes Antropológicos, ano 22, n. 46, p. 131-157, jul./dez. 2016.

CARVALHO, Renata C. O.; AVILA, Marco Aurélio. O Turismo Étnico e seus reflexos nos Terreiros de Candomblé Angola em Salvador - Bahia. Politicas Culturais em Revista, v. 5, n. 1, p. 58-89, 2012.

CHARI, Sharad; DONNER, Henrike. Ethnographies of activism: A critical introduction. Cultural Dynamics, n. 22, v. 2, p. 75-85, New York: Sage, 2010.

CHASTEL, André. La notion de patrimoine. In: NORA, P. (Dir.). Les lieux de mémoire, Paris: Gallimard, v. 1, p. 1433-1469, 1997 [1986].

COMAROFF, Jean; COMAROFF, John. Ethnography on an awkward scale: Postcolonial anthropology and the violence of abstraction. Ethnography, v. 4, n. 2, p. 147-179, 2003.

COMAROFF, Jean; COMAROFF, John. Etnicidad S. A. Madrid: Katz Editores, 2011. 
CRUZ, Ana Paula. "Viver do que se sabe fazer": memória do trabalho e cotidiano em Santiago do Iguape (1960-1990). 2014. Dissertação (mestrado em História) - Programa de pós-graduação em História, Universidade Estadual de Feira de Santana, Feira de Santana, 2014.

GONÇALVES, José Reginaldo Santos. O patrimônio como categoria de pensamento. In: ABREU, Regina; CHAGAS, Mário (Orgs.). Memória e patrimônio: ensaios contemporâneos. Rio de Janeiro: DP\&A, 2003. p. 21-29.

GONÇALVES, José Reginaldo Santos. Os limites do patrimônio. In: LIMA FILHO, Manuel; ECKERT, Cornelia; BELTRÃO, Jane (Orgs.). Antropologia e patrimônio cultural: diálogos e desafios contemporâneos. Blumenau: Nova Letra, 2007. p. 239-248.

GONÇALVES, José Reginaldo Santos. As transformações do patrimônio: da retórica da perda à reconstrução permanente. In: TAMASO, Isabela; LIMA FILHO, Manuel. (Orgs.). Antropologia e patrimônio cultural: trajetórias e conceitos. Brasília: ABA, 2012. p. 59-73.

GOW, Peter. Mito e mitopoiese. Cadernos de campo, n. 23, p. 187-210, 2014.

GRÃOS DE GRIÔ. Termo Griô: Conceito, História, Tradição e Reinvenção. Disponível em: <http://graosdeluzegrio.org.br/acao-grio-nacional/o-que-e-grio/>. Acesso em: 16 jun. 2020.

GREENWOOD, Davyd J. Tourism as an agent of change: A Spanish Basque case. Ethnology, v. 11, n. 1, p. 80-91, 1972.

GREENWOOD, Davyd J et al. Unrewarding wealth: the commercialization and collapse of agriculture in a Spanish Basque town. Cambridge: Cambridge University Press, 1976.

GRÜNEWALD, Rodrigo de Azeredo. Turismo e Etnicidade. Horizontes Antropológicos, Porto Alegre, ano 9, n. 20, p. 141-159, out. 2003.

HOBSBAWM, Eric; TERENCE Ranger. A invenção das tradições. Rio de Janeiro: Paz e Terra, 1997.

LATOUR, Bruno. Reagregando o social: uma introdução à teoria do ator-rede. Salvador: Edufba, 2012.

MARINHO, Thais Alves. As nuances do reconhecimento mussuca: entre a folclorização e a etnicização. In: DUMAS, Alexandra G.; BRITTO, Clóvis C. (Orgs.). Corpo Negro: Nadir de Mussuca, Cenas e Cenários de uma mulher quilombola. São Cristóvão: Ed. UFS, 2016. p.153-177.

MELLO, Marcelo. Reminiscências dos quilombos: territórios da memória em uma comunidade negra rural. São Paulo: Ed. Terceiro Nome, 2012.

MEYER, Birgit. Como as coisas importam: uma abordagem material da religião. Porto Alegre: Editora da UFRGS, 2019.

NO MUNDO DAS UMBANDAS. Novos Estudos 03 - Umbanda Po-

pular. Disponível em: <http://www.nomundodasumbandas.com. br/2015/07/novos-estudos-03-umbanda-popular.html>. Acesso em: 16 jun. 2020. 
OLIVEIRA, J. C. Entre plantas e palavras: modos de constituição de saberes entre os Wajãpi (AP). 2012. Tese (Doutorado em Antropologia Social) - Faculdade de Filosofia, Letras e Ciências Humanas, Universidade de São Paulo, 2012.

OLIVER-SMITH, Anthony; ARRONES, Francisco Jurdao; ARCAL, Jose Lison. Tourist development and the struggle for local resource control. Human Organization, v. 48, n. 4, p. 345-351, 1989.

PARÉS, Luís Nicolau. A Formação do Candomblé: História e Ritual da Nação Jeje na Bahia. Campinas: Editora da Unicamp, 2006.

PINHO, Osmundo. A antropologia no espelho da raça. Revista Novos Olhares Sociais, v. 2, p. 99-118, 2019.

PISSOLATO, Iacy. O Xarope de Dona Vardé e outras receitas de resistência no Quilombo do Kaonge. No prelo, s/d.

PITROU, Perig. Ação ritual, mito, figuração: imbricação de processos vitais e técnicos na Mesoamérica e nas terras baixas da América do Sul. Revista de Antropologia, São Paulo, n. 59, v. 1, p. 6-32, abr. 2016.

POULOT, Dominique. La morale du musée: 1789-1830. Romantisme, n. 112, p. 23-30, 2001.

SAHLINS, Marshall. O "pessimismo sentimental” e a experiência etnográfica: por que a cultura não é um "objeto" em via de extinção (parte I). Revista Mana, n. 3, v. 1, p. 41-73, 1997.

SANTOS, Aline dos. Portfólio Pedagógico. Programa de Educação Tutorial - Pet. Conexões de Saberes, Centro de Ciências Agrárias, Ambientais e Biologicas - (CCAAB) UFRB. Cruz das Almas, 2011.

SANTOS, Antônio Bispo dos. Colonização, quilombos: modos e significações. Brasília. INCTI/UnB, 2015.

SANTOS, Cléia Costa dos; JOVELINO, Rosane Viana; SILVA, Gilmar Bittencourt Santos. Conselho Quilombola e sua função deliberativa no planejamento do estado: o caso da Bacia e do Vale do Iguape. Bahia Análise \& Dados, v. 2, n. 28, p. 178-195, 2019.

SANTOS, Milton. Metamorfoses do espaço habitado. São Paulo: Hucitec, 1994.

SAUMA, J. Palavras carnais: sobre re-lembrar e re-esquecer, ser e não ser, entre os Filhos do Erepecuru. Revista de Antropologia, v. 59, n. 3, p. 150-173, 2016.

SMITH, Valene L. (Ed.). Hosts and guests: the anthropology of tourism. Philadelphia: University of Pennsylvania Press, 2012 [1989].

SILVA, Breno; FERNANDES, Mariana; REIS, Poliana. Relatório antropológico de caracterização histórica geográfica do território das comunidades remanescentes de quilombo Caonge, Calembá, Dendê, Engenho da Ponte e Engenho da Praia, município de Cahoeira,BA. Salvador: INCRA, 2014.

SILVA, Doris Regina Barros da. Os contos e os pontos: o lugar do saber e os saberes que tem lugar nas rodas da pedagogia griô. Revista Forum Identidades, ano 6, vol. 11, p. 56-69, jan./jun. 2012. 
SZTUTMAN, Renato. Reativar a feitiçaria e outras receitas de resistência-pensando com Isabelle Stengers. Revista do Instituto de Estudos Brasileiros, n. 69, p. 338-360, 2018.

TAVARES, Fátima; BASSI, Francesca. Efeitos, símbolos e crenças. Considerações para um começo de conversa. In: TAVARES, Fátima; BASSI, Francesca (Orgs.). Para além da eficácia simbólica. Estudos em ritual, religião e saúde. Salvador: Edufba, 2013. p.17-28.

TAVARES, Fátima; CAROSO, Carlos; BASSI, Francesca; PENAFORTE, Thais; MORAIS, Fernando. Saberes e fazeres terapêuticos quilombolas, Cachoeira, Bahia. Salvador: EdUFBA, 2019.

VARINE, Hugues de. As raizes do futuro: o patrimônio a serviço do desenvolvimento local. Porto Alegre: Medianiz, 2012.

UNESCO. Convention for the Safeguarding of the Intangible Cultural Heritage, Paris, 17 October 2003. Brasília: Ministério das Relações Exteriores da República Federativa do Brasil, 2006.

VATIN, Xavier. O Desenvolvimento do 'Turismo Étnico' na Bahia: o Caso da Cidade de Cachoeira. Trabalho apresentado na 26a Reunião Brasileira de Antropologia. Bahia, 2008.

WAGNER, Roy. A invenção da cultura. São Paulo: Cosac Naify, 2010. 